\title{
Research ethics: Examining the tension between principlism and rational self-interest in a neoliberal university context
}

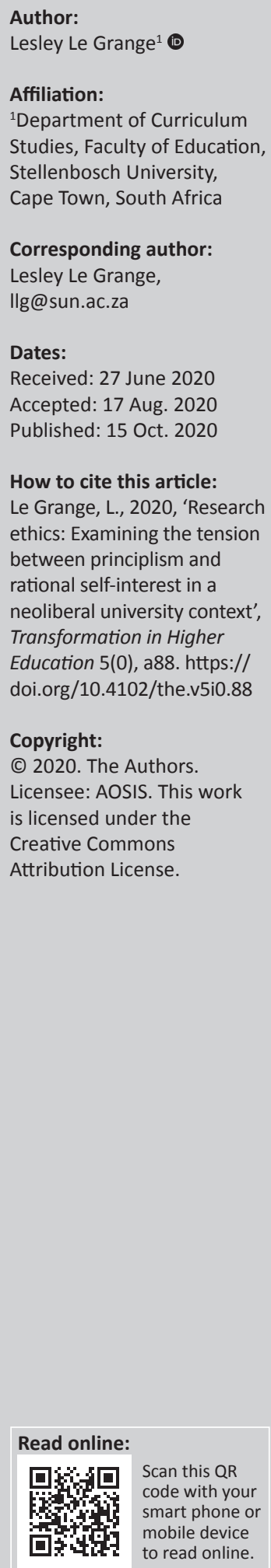

Background: The reconfiguration of the contemporary university as a consequence of the (re)ascendency of neoliberal politics has not escaped South African universities. The higher education landscape in the country is characterised by performativity regimes - discourses on quality assurance, efficiency and accountability abound and so too modes of regulation based on rewards, sanctions and censorship.

Aim: The article explores the extent to which these two conflicting ethical discourses (principlism and rational self-interest) have a bearing on a South African case that resulted in an investigation into research misconduct at a South African university.

Setting: The broader setting is the neoliberal university. The specific setting is Stellenbosch University. As is the case with many western(ised) universities, this higher education institution has not escaped neoliberal influences.

Methods: The methods used combine conceptual exploration supported by a case study. The usage of case in this study does not refer to how it is typically used in qualitative research. The focus is not on a bounded system but on the narrative essence of the case, more akin to the usage of 'case' in law and medicine.

Results: The philosophical tensions between the two discourses on ethics might be overcome by refocusing the university on the public good, instead of valorising the individual.

Conclusion: Overcoming the philosophical tensions between the two discourses might only be possible through recognising the value of an immanent rather than a transcendent ethics.

Keywords: ethical regulation; immanent ethics; neoliberal; principlism; rational self-interest.

\section{Introduction}

The landscape of the contemporary university has changed radically because of the adoption of neoliberal policies and the emergence of knowledge societies driven by the global knowledge economy. According to Sutherland-Smith and Satmarsh (2011), contemporary universities have been reconfigured as engines of economic growth, which has led to the erosion of ethical principles, and conduct in universities is 'now driven by corporate interest, competitive individualism, and the intensification of audit and surveillance regimes'. Ball (2003) points out that performativity produces fabrications, that is, the presentation of self within particular registers of meaning in which only certain possibilities of being have value. In the neoliberal university, we are witnessing a phenomenon coined by Haggerty (2004), called 'ethics creep'. Ethics creep refers to the expansion of ethical regulation from the biomedical sciences to the human and social sciences - referred to by some as the biomedicalisation of the humanities and social sciences. About ethics creep, Haggerty (2004) writes:

$[I] t$ involves a dual process whereby the regulatory structure of the ethics bureaucracy is expanding outward, colonizing new groups, practices, and institutions, while at the same time intensifying the regulation of practices deemed to fall within its official ambit. (p. 394)

For Guta, Nixon and Wilson (2013), what we are witnessing in the contemporary (neoliberal) university is a shift from professional ethics rooted in academic norms to the codification of ethics through ethical regulation by external review bodies. This shift, they argue, has created consternation amongst researchers regarding issues listed here.

- Ethical reviews are often reduced to tick-box exercises.

- Works of review boards are not transparent - they are often secretive. 
- There is a lack of consistency in interpretation and application of review boards.

- Some forms of inquiry are burdened and others are privileged by ethical reviews.

- Approaches to ethics are rooted in positivism and a biomedical conception of harm.

- Ethics creep has been linked with the erosion of academic freedom.

The latter concern is relevant to the case that will be described, and with particular reference to how ethical regulation can result in censorship. Censorship in this context refers to restrictions placed on the freedom of the researcher or author to speak in particular ways (Guta et al. 2013). The case that will be presented later relates to an investigation into research misconduct (in relation to ethics) at Stellenbosch University in South Africa. Stellenbosch University is South Africa's second oldest university and one of a few research-intensive universities in the country. The university is historically white and Afrikaans but its monocultural identity has been (and is being) challenged in post-apartheid South Africa. The case provides a rare opportunity for learning and reflection because the information about the case is already in the public domain. But, such learning and reflection could have broader application given the normalising and homogenising effects of neoliberal policies on the contemporary university.

Kruger, Ndebele and Horn (2014) point out that the first documented cases of ethical review on the African continent were recorded in South Africa. The first research ethics committee (REC) on health research that was established in South Africa was at the University of Witwatersrand in 1966. Today, there are RECs at most of the South African public universities and at two private higher education institutions and 17 non-academic institutions (Kruger et al. 2014). At Stellenbosch University, there are currently three different RECs: one for human research, one for biomedical research and one for animal research.

In this article, I discuss two oppositional ethical discourses (principlism and rational self-interest), which co-exist in the contemporary (neoliberal) university, and examine the extent to which these discourses play out in the Stellenbosch University case involving an investigation into 'research misconduct' by a PhD student. I suggest that ameliorating the tensions produced by the two competing ethical discourses might only be possible through recognising the value of an immanent instead than a transcendent ethics. I divide the discussion of the rest of the article into the following sections:

- Principlism and rational self-interest

- The Stellenbosch University case

- Complexity of ethics in the contemporary university

- Conclusion: Towards an immanent ethics.

\section{Principlism and rational self-interest}

In her article entitled Confessions of an ethics committee chair, Halse (2011:239) shifts the angle of vision from the procedural, bureaucratic effects of regulatory ethics to an interrogation 'of the possibilities of being in the academy and being an ethical researcher within the ethics of principlism'. Principlism is an ethical framework based on normative principles that guide research performed on human subjects. The most well-known ethical principles used to guide research involving human subjects are those specified by Beauchamp and Childress (1985): autonomy (the ability of a rational person to make a decision to participate in research or not), beneficence (the benefits of the research justifying its risks), non-maleficence (no harm will to be done to research subjects) and justice (that the benefits and risks of research should be fairly distributed). Halse (2011) argues that as an ethical framework, principlism is not based on a single, coherent ethical theory but a set of principles which is a blend of different philosophical perspectives: Kant (autonomy), Mills (beneficence), Gert (non-maleficence) and Rawls (justice). Beauchamp and Childress (1985) pointed out the four principles that they specified were not intended to be a general moral theory but to provide a framework to assist those working in medicine to identify moral problems and to make decisions in solving such problems.

It is important to note that principlism has its origin in the field of medicine. However, as a consequence of the biomedicalisation of the social sciences and humanities, it has been applied more generally. Principlism has been critiqued by several scholars. Walker (2009) distinguishes between principlism as a descriptive claim and principlism as a normative claim. Principlism as a descriptive claim relates to the actual moral norms shared by all morally serious people. Principlism as normative claim concerns what moral norms ought to be shared by all morally serious people. Walker (2009) argues that as both a descriptive claim and a normative claim, principlism based on the four principles specified by Beauchamp and Childress is inadequate. He avers that the four principles do not capture common morality because there are culture-specific moral norms which Beauchamp and Childress's principles do not incorporate. Principlism as normative claim means that all moral norms that are universalisable are included. Walker (2009) argues that if this is true then principlists need to explain why morality is so narrowly constrained (to only include Beauchamp and Childress's principles). Walker proposes two solutions to address principlism as descriptive claim and normative claim. He suggests that there are only two options for principlists: to add more universalisable principles so that common morality is more adequately captured; or, to move to more culturespecific versions of principlism, which would in most cases include more than the current four principles.

De Marco (2005) argues that principlism has resolved moral dilemmas in two basic ways: only one prima facie obligation entails a genuine obligation; and, all obligations are genuine, so a moral residue results, which manifests in moral regret or a derived moral obligation such as compensation. For example, a medical practitioner promises to take her partner to dinner on his birthday, but receives a call to say that she is 
needed at the hospital because of an increase number of COVID-19 patients. The doctor has a moral dilemma, her promise to her partner versus her obligation to save lives. De Marco (2005), argues that for principlists, there is only one genuine obligation and that is for the medical practitioner to save lives. But this results in moral regret because a promise has been broken. The medical practitioner could of course do something such as to book a weekend away for the two of them as a means of compensation. De Marco (2005) argues that such a scenario is unsatisfactory and proposes that a new principle be added to the four established principles, the mutuality principle. This principle involves the process of ensuring the mutual enhancement of all basic principles. He argues that the mutuality principle adds coherence to a system of moral values. For De Marco (2005), 'mutual enhancement means, at the minimum, that the enhancement of one value should not be at the cost of another'. So in this example, the conflict could have been avoided by the medical practitioner saying to her partner that they would go to dinner to celebrate the partner's birthday, but if she is called to the hospital she would have to postpone the dinner and would also say what the alternative arrangement might be.

Not only does principlism have its origin in the field of ethics, but debates on principlism have also mainly occurred in the field of medical ethics. However, principlism has migrated into other fields through ethical regulation, which is the consequence of ethics creep. In this migration into other fields, the critical debates on principlism have not been incorporated and ethical regulation-based on Beauchamp and Childress's principles continue to be used whether in a modified or revised form. In fact, principlism has become the foundation of regulatory frameworks and drives decisionmaking of university RECs in many universities of anglophone countries. Different countries and universities have adapted the sets of principles mentioned above to guide research conducted on or with human subjects by their academics and students. For example, Australia's National Statement on Ethical Conduct in Human Research (NHMRC, ARC \& UA 2007) states that research conducted in the country should be guided by the following principles: research merit and integrity (that research should be theoretically, empirically and methodologically rigorous), justice, beneficence and respect (that the privacy, confidentiality and dignity of participants are respected). In South Africa, the Department of Health (2015) has identified the following ethical principles that should guide health research: beneficence and non-maleficence, distributive justice (equality) and respect for persons (dignity and autonomy). According to Stellenbosch University's standard operating procedure (SOP) for its REC, '[s]ocial, behavioural and educational research, all provisions for health research in national policies and laws should be adhered to in so far as they are relevant to research conducted in the social sciences and the humanities' (Stellenbosch University 2019).

Halse (2011) contrasts the principlism of regulatory ethics with that of rational self-interest and argues that the former is the antithesis of the latter. She points out that rational selfinterest is a philosophy that originated in the work of English philosopher Henry Sigwick (1874) and was developed further by others, including Ayan Rand (1964). Rational selfinterest is a normative ethics that gives primacy to the personal interests of the researcher (in this instance) so that the well-being of others is secondary. Halse (2011), however, points out that rational egoism or self-interest ${ }^{1}$ is not a licence to do as one pleases because the interest must be driven by a rational reason. Nor does it mean that rational judgements and the actions that flow from them are immoral. As Baier (1993) writes:

[Rational egoists are not] self-centred, inconsiderate, unfeeling, unprincipled, ruthless self-aggrandizers, pursuers of good things in life whatever the cost to others, people who think about themselves or, if about the other, than merely as a means to their own ends. (p. 7)

The interest of the other is, however, subordinate to that of the self.

Giving attention to the notion of rational self-interest is important because it 'has become the defining feature of the moral economy of universities under neo-liberalism and new public management' (Halse 2011:248). Much has been written about the influence of neoliberal ideology on the contemporary university, which is characterised by performativity regimes, audit cultures, economic rationalism, placing value on the individual, managerialism and so forth (see Le Grange 2009; Olssen \& Peters 2005; Peters 2007, 2013; Rose 1999). There is no need to rehearse this discussion here. Suffice it to say, neoliberal ideology has radically changed the nature of the university in relation to its management, academic organisation, systems of regulation and control, introduction of incentives, changes to promotion criteria, workloads, behaviours of academics and so forth.

Why is the distinction between principlism and rational selfinterest pertinent to our discussion? Halse (2011) argues that the ethics of principlism and rational self-interest are two competing and opposing discourses on ethics that co-exist in the contemporary university. Moreover, that the irreconcilable philosophical conflict of these discourses raises the critical question of whether it is possible to be an ethical researcher in the contemporary university. The core of the conflict is the fact that rational self-interest overrides the notion of the singular responsibility to others, which is at the heart of an ethics of principlism.

The discussion on principlism and rational self-interest as well as matters discussed in the introduction provide the backdrop for examining the Stellenbosch University case with the aim of exploring to what extent principlism as ethics and rational self-interest have a bearing on the case; what is the possibility of being an ethical researcher in a context such as Stellenbosch University; how to register the possibility of an immanent ethics in the contemporary university.

1.Rational self-interest and rational egoism are used synonymously in this article. 
BOX 1: The summary.

About a decade ago former PhD candidate Mareli Stolp registered to study in the Department of Music at Stellenbosch University, South Africa. She was the first student to register for what was called an 'integrated PhD' study. The 'integrated PhD' combined elements of performance typical of the D. Mus. (Doctor of Philosophy) degree and theoretical exploration typical of the PhD offered by the university. ${ }^{2}$ Methodologically, Stolp used a narrative genre which infused features of auto-ethnography. Such a methodological approach was 'new' to research in Music at South African universities.

In the early stages of her study, she became aware of tensions amongst academic staff members in the Department of Music, which included disagreements about the nature of the 'integrated PhD'. Her research proposal was supported by her academic supervisor and approved by the Faculty of Arts and Social Science Research Committee. However, there were objections to the proposal by three members of the Department of Music and they withdrew from Stolp's doctoral Admissions Committee. The upshot of this was that two of her practical supervisors resigned.

Mareli Stolp graduated in 2012. The degree was awarded following the examination of the written thesis by three independent examiners appointed by the university's Senate and a successful viva voce defence. After the degree was awarded, as is customary at the university, the thesis was uploaded on Stellenbosch University's repository (SunScholar) and made electronically accessible via Google Scholar. A few months (in May 2013) after the award of the degree the thesis was put under embargo with restricted access by the university's Division Research Development (DRD) because of a complaint lodged by the Chair of the Department of Music who claimed that Stolp had committed 'ethical transgressions'. The complaint was that Stolp named several members of the Department of Music in her thesis and used recordings of artists who performed at the university's conservatory without their knowledge and consent and did not adhere to the principle of anonymity. Stolp and her supervisor were not informed that the thesis had been placed under embargo at the time it was done. She was first made aware of this development when her supervisor received a letter from the university's Research Integrity Officer (RIO) that an investigation of 'research misconduct' had been instituted, following a complaint that was submitted.

The Vice-Rector ${ }^{3}$ (Research and Innovation) appointed (via the DRD) a committee of three senior professors ${ }^{4}$ (one retired) of the university to investigate the complaint. The IC found that Stolp was not guilty of research misconduct in the sense that data were fabricated, falsified or that the work of others had been plagiarised. However, the IC did find that there were ethical breaches in that there were people identified or identifiable in the thesis who were not fully aware of the role they had played in the research. Based on its findings the IC recommended (1) that the thesis be made available on the SunScholar repository on condition that the names of those identified or identifiable are blacked out; (2) that the Chair of the Department of Music would have an opportunity to write a rebuttal and that this rebuttal will be uploaded with the thesis; and (3) that recordings used in the research should be removed from the public domain or that Stolp should obtain the necessary approval from copyright owners.

But, the saga did not end here. Several months following the completion of the work of the IC, the internal examiner (an extraordinary professor at Stellenbosch University), Chris Walton contacted several parties (including the IC) in the university to express his dissatisfaction with the investigation and its outcome. When he did not receive a desired response, he contacted and lodged a complaint with ombudsman of the university. The ombudsman conducted his own investigation and upon completion thereof, he instructed the university management to make the original thesis (without names blacked out) accessible via the university's repository SunScholar. Members of the university management and the Department of Music requested a report from the ombudsman but he failed to produce one. As a consequence of unsuccessful attempts to gain access to the ombudsman's report, further appeals were independently lodged by the Chair of the Department of Music and a colleague, which set in motion an investigation by the Council of Stellenbosch University. The Council appointed an ad hoc committee comprising four senior academics from outside the Faculty of Arts and Social Science and a retired judge of South Africa's Supreme Court of Appeal who chaired the committee. This committee's findings echoed the decision of the original IC that Stolp 'had breached certain ethical norms and principles' and that the decision of the ombudsman was 'fatally flawed'. Based on these findings, the Executive Committee of the Council instructed the Rector's management team to

'reinstate' the decision of the original IC that the thesis should be accessible in a restricted manner so that identified and identifiable persons are not revealed.

Source: IC report, Horn, L., Van Niekerk, A., Theron, T., Swartz, L. \& Le Grange, L., 2016, 'Power and ethics in humanities research: A response to Stolp', Acta Academica 48, 1-15. https://doi. org/10.18820/05872405/aa48i2.2; Lüdemann, W., 2017, 'Power and ethics in humanities research: Another response to Stolp', Acta Academica 49(2), 1-10; Stolp, M., 2016a, 'Report to the academy: Power and ethics in humanities research', Acta Academica 48(1), 1-26. https://doi.org/10.18820/24150479/aa48i1.1; Stolp, M., 2016b, 'Response to the academy', Academica Academica 48(2), 16-17. https://doi.org/10.18820/05872405/aa48i2.8; Walton, C., 2017, 'Of ethics and incompetence', Acta Academica 49(1), 1

IC, Investigating Committee.

\section{The Stellenbosch University case}

My invocation of the term 'case' is not akin to its conventional usage in case study research whereby case study refers to an inquiry into a contemporary phenomenon in a real-life context and uses a range of different methods. My usage of case relates to what Herreid (1997:92) has so succinctly put, 'cases are stories with a message'. Demez (2015) elaborates on this understanding of case: 'The emphasis here is not on the border but on the narrative essence of the case, in relation with a theoretical issue, beyond the didactic one (the message)'. This understanding of case is relatively unexplored in higher education studies and is probably more closely related to the usage of 'case' in law and medicine.

The Stellenbosch University case therefore is a narrative constructed to illuminate the tension between principlism and rational self-interest in social research. The narrative is constructed from five journal publications produced on it (Horn et al. 2016; Lüdemann 2017; Stolp 2016a, 2016b; Walton 2017). It begins with a summary (see Box 1) of the events as they occurred chronologically and augmented with direct quotes from the articles and the Investigating Committee (IC) report. ${ }^{5}$

2.According to the university calendar, "the unique nature of the integrated option is derived from the coherence and interdependency of the study of the creative processes and theoretical dimensions of the research leading to an origina contribution to knowledge of and insight into the arts'.

3.Vice-Rector is the equivalent of Deputy Vice-Chancellor used at many Commonwealth universities.

4.The senior professors were Leslie Swartz (Distinguished Professor of Psychology), N. Botha (retired and now deceased Professor of Social Work) and Lesley Le Grange (Distinguished Professor of Education).

5.I declare that as author of this article, I was a member of the IC. In performing my role as investigator, I was as objective as I could be and in writing this article I have
Subsequent to the completion of the original IC report a number of articles were published on the case in question. The first was an article by Stolp (2016a) in which she argues that ideological differences in the Department of Music, which also reared its head in the proposal approval stage of her thesis, was the catalyst for what unfolded in this instance. She avers that academic freedom and freedom of speech in the post-apartheid South African university is being curtailed as a consequence of the 'managerial turn' in university management and in particular the utilisation of ethical regulation in humanities research. She argues that in her own case, 'managerial power mechanisms co-opted ethics into processes of censure and censorship' (Stolp 2016:1). Moreover, she points out that ethical regulation in the contemporary university is closing down spaces for doing what she terms 'risk-taking research'.

Stolp's thesis was a critique of the status quo in departments of music at universities such as Stellenbosch University and performances that are privileged in such institutions, which are largely based on European classical music. The status quo excludes or marginalises African and local South African music and genres such as improvisational jazz. As Stolp (2016) writes:

The institutional critique presented in the dissertation dealt with issues such as a perceived lack of institutional engagement with contemporary art music repertoire (at curriculum level, as

attempted to do the same. However, I shall declare some broad personal interests that may have impacted on what is reported in this article. It is my view that transformation at Stellenbosch University has been slow and that not much has been done to change the culture of the university in post-apartheid South Africa. been done to change the culture of the university in post-apartheid South Africa.
So I have an interest in seeing the university being transformed more rapidly. I also Sol have an interest in seeing the university being transformed more rapidly. I also humans or the more-than-human world is harmed. I leave the reader to decide on humans or the more-than-human world is harmed. I leave the reader to decide on
the extent to which my beliefs and interests have influenced what is reported in the article. 
well as in terms of concept programming); inadequate support for new music by South African composers; and limited exploration of contemporary art practices such as conceptual art, improvisation, intermediality and transdisciplinary work. An attempt was made to address these perceived issues by performatively engaging with them: performing music seldom (if ever) heard in South Africa (especially in concert offering of institutions such as Stellenbosch University) ... (p. 11)

Stolp argues that she felt ethically obligated to offer the critique presented in her thesis and to use the 'new' methodology (presumably to disrupt the status quo in music research in some South African universities) in her study. She writes:

\begin{abstract}
Although I was well aware that the content of my dissertation was controversial, I felt an ethical imperative to risk addressing certain issues that I believed were pertinent in South African art music culture. I also felt strongly committed to exploring a new type of research and to demonstrate its possible uses in doctoral studies in music. The final thesis was a result of exploration, investigation and consideration of key issues, amalgamated in a document and subjecting the work and its author to a protracted investigation process did not, in my opinion, serve a scholarly purpose ... (pp. 12-13)
\end{abstract}

The first reply to the article published by Stolp in 2016 was co-authored by the RIO, Chairperson of the Senate's Ethics Committee, the Senior Director: DRD, and two members of the original IC. ${ }^{6}$ In their response to Stolp, the authors (Horn et al. 2016) do several things: acknowledge that the university committed some procedural faux pas and had deviated from its policies; point out that Stolp misunderstood several matters; comment critically on Stolp's claim that in her case ethical regulation was used as a power mechanism for censure and censorship; and comment critically on Stolp's lack of reflexivity in conducting narrative or autoethnographical research. I shall focus on the latter two.

Horn et al. (2016) point out that Stolp's PhD proposal was not submitted for any formal process of ethics review or approval, despite the fact that a Stellenbosch University policy was in place at the time which stated the following:

International guidelines for the need for ethics approval of nonhealth related research e.g, social science research involving human participants are less clear. However, research involving direct interaction with human subjects or the capturing of any personal information should be approved by an ethics committee. [...] (pp. 6-7)

Research involving human participants must comply with the following principles:

[...] ensure research participants are well informed on the purpose of the research and how the research results will be disseminated and have consented to participate, where applicable, ensure research participants' rights to privacy and confidentially $[\mathrm{sic}]$ are protected; ensure the fair selection of the research participants be preceded by a thorough risk benefit. [...] (pp. 6-7)

6.The third member of the IC was deceased at the time.
Based on Stolp's arguments (presented earlier), one could infer that she did not deem it necessary to subject her proposal to ethical review because she felt that the ethical imperative to critique music culture and music research in South African universities superseded subjection to ethical regulation. However, Horn et al. (2016) argue that academic freedom does not have to be sacrificed on the altar of research ethics. Horn et al. (2016) write:

As is clear in Stolp's article, the actions taken with respect to this dissertation, after the investigation ${ }^{7}$ was concluded, were regarded as 'censure and censorship'. We do not agree with this perspective and as stated previously, believe that both principles of academic freedom, and research ethics could have been fulfilled simultaneously in this dissertation. This dissertation could have leveled a powerful critique at both Stellenbosch University and the Department of Music, including commentary on the apartheid legacy of the Music Department and issues related to transformation, without making this critique personal to the point where individuals were either directly or easily identifiable. (p. 12)

Concerning Stolp's perspective that the methodology used justified identifying person's in the research, Horn et al. (2016) do not agree with her perspective. Horn et al. (2016) quote directly from the IC report about the authors' views on the ethics of doing narrative or auto-ethnographical research:

From the committee's conversation with Dr Stolp, and from the way in which the thesis itself was written, the committee came to the view that Dr Stolp appears to have conflated two issues. There is a difference between taking subjectivity seriously and giving due weight, and of selectively privileging the subjective experiences of the author. Though it is correct to say that a subjective interpretation of events is important to understand and to respect and embrace, this is not the same as implying that the views of the author (in this case Dr Stolp) should not be subject to the same skeptical scrutiny as those of others. Dr Stolp does address this issue distally in her early chapters, but there are occasions when she discusses her findings that she does not seem to entertain as seriously as she could the possibility that her interpretation is but one of many ways of understanding what has occurred. This is a difficult issue, as it is her right methodologically and intellectually to use her own subjectivity. It was clear from our discussions with her that Dr Stolp felt to some degree victimized by the Department of Music, and this was indeed part of her experience. What she seems to have taken less cognisance of, in her writing of the thesis, was her own power and agency (admittedly within the context of asymmetrical power relationships in which she was structurally in a less powerful position). [...] (pp. 11-12)

Horn et al. (2016) note that there is a growing trend in autoethnographical research and that this should be welcomed. However, as Wall (2008) reflects on her own autoethnography, she writes:

$[T]$ here is a need to be concerned about the ethics of representing those who are unable to represent themselves in writing or to offer meaningful consent to their representation by someone else. (p. 49)

Stolp was asked by the journal Acta Academica to write a rejoinder to the Horn et al. (2016) reply. Stolp's (2016b) 7.The investigation referred to here is that of the original ic. 
rejoinder was brief and the essence thereof is best captured in her own words:

I agree with many of the points raised in this response, although I would also continue to argue that the particularities of specific situations warrant more contextualised applications of ethicsrelated theories than what is, in my view, generally the case in the Stellenbosch University's response to my article. While there are some points I disagree with, and while I remain convinced of the validity and ethicality of my own work, I will not attempt to comprehensively engage the entirety of the response here: this important and ongoing debate will benefit, I believe, from contributions that seek to also to move beyond the specificity of a single case study and engage a broader field of inquiry. (pp. 16-17)

But, with respect to replies and rejoinders, the dust had not settled. In 2017 there were two further replies written to the journal Acta Academica from (1) the internal examiner (extraordinary professor at Stellenbosch University and academic at the Basel University of Music, Switzerland) Chris Walton and (2) the Chair of the Department of Music, Winfried Lüdemann. In a short reply, Walton (2017) raises two issues. Firstly, he states that he agrees with Horn et al. (2016) that Stolp's thesis raised complex issues of ethics and agency. However, he points out that these issues were the subject of robust deliberations by the examiners and unanimously resolved during the viva voce by them. Walton's issue is that none of the examiners were asked for their opinion during the investigation. Walton is correct and makes a valid point. The second issue that Walton (2017) raises is what he claims is the fundamental issue at stake in the case. In his own words, he describes the issue as follows:

How can a music department be allowed to file a complaint against a doctoral student of its own, whose topic it has accepted, whose research it has supported, whose examiners it has appointed, and to whom it has already agreed to award the degree? At what point does departmental incompetence descend into unethical conduct? There is indeed scope here for a largescale investigation of academic ethics. But its focus should be on the department, not its student. (p. 1)

Lüdemann (2017) raises two interrelated points that are pertinent to the discussion. He contests Stolp's claim that tensions amongst staff members in the Department of Music were the catalyst for the events that unfolded, leading to an investigation into possible research misconduct. Lüdemann points out that in his complaint he clearly spelt out that the complaint related to ethically questionable research and quotes from his own written complaint to support his view. Lüdemann (2017) states that his complaint was motivated by a:

$[D]$ eep sense of responsibility and duty as Chair of the Department to stand up for the personal dignity and rights of my colleagues and students implicated in the dissertation, the reputation of the Music Department and, equally important, the integrity, ethical standards and reputation of research conducted at the University of Stellenbosch. No other issues whatsoever are at stake here. No issues brought to the fore by any party should deflect or detract from this fundamental concern. (pp. 3-4)
Lüdemann (2017) also points out that the above statement was known by Stolp and nowhere does she produce any evidence that reflects that this statement was disingenuous. Moreover, Lüdemann (2017) notes that if indeed resistance to transformation at disciplinary or institution level was dealt with by using ethical regulation as a power mechanism for censure and censorship, then it would imply that there was collusion between the various structures of the university to make her allegation convincing. Such collusion was unlikely because all committees conducted their work independent from one another.

The main arguments arising from the five articles published in the journal Acta Academica were presented in the chronological order in which the different papers were published in the journal and not arranged in an order that reflects the (de)merits of the arguments. What the case highlights is the complexity of ethics in the contemporary university, a discussion to which I shall (re)turn next.

\section{Complexity of ethics in the contemporary university}

The case highlights the complexity of ethics in the contemporary university and the difficulties of being in the university and being an ethical researcher. Stolp (2016a) outlines a convincing argument for why she contends that ideological struggles in the Department of Music acted as catalyst for invoking ethical regulation as a power mechanism for censure and censorship of her thesis. In all written documentation on the case, there is no instance where any author denies that there were ideological struggles in the Music Department. In fact, the ideological differences are acknowledged and noted in the report of the original IC. That tensions amongst staff in the Department of Music spilled over onto her study is also not denied by anyone. The lack of transformation at Stellenbosch University (and other South African universities) is well documented and laid bare by students' protests of 2015 and 2016, the \#RhodesMustFall and \#FeesMustFall campaigns and more localised movements linked to these such as the \#OpenStellenbosch movement (for a more detailed discussion see Le Grange 2016). As a consequence of colonialism, South African universities inherited European models of academic organisation (Le Grange 2014) and so it is unsurprising that much of what is taught or learned and the performances organised in or by the Department of Music at Stellenbosch University are Eurocentric. Stolp's critique of the Eurocentrism prevalent in the Department of Music and her actions to move marginalised genres, particularly local ones, to the centre, are politically and ethically admirable. Furthermore, her claim that ethical regulation can be used for purposes of censure and censorship is not far-fetched. Literature supports such a view (see Guta et al. 2013) and she draws on this literature in support of her argument. From, Stolp's vantage point, the way she connects the dots of the events that unfolded is plausible. 
What Stolp's (2016a) argument does (and does no more than this) is to register the possibility of ethical regulation being used in the neoliberal university as a smokescreen for some other agenda. However, Stolp's claim of being an ethical researcher might be less convincing. Here my earlier discussion on principlism is worth returning to. I discussed how principlism as ethics has become infused into regulatory frameworks of nation states, ethics review boards, RECs and so on. However, even though ethical principles, such as beneficence, non-maleficence, justice, autonomy and respect, have become co-opted into ethical regulatory frameworks, such as in policies, SOPs and so forth, these principles predate neoliberal ethical regulation and call on researchers and others who interact with human subjects to take these principles seriously and to uphold them. Even if principlism as multiprincipled theory were extended by adding more principles, be they more universalisable principles or culture-specific principles as suggested by Walker (2009), or the mutuality principle suggested by De Marco (2005), such modifications would not exonerate her from obligations to uphold the principles specified by Beauchamp and Childress (1985). It is Stolp's breach of at least some of these principles (principles which stand or hold outside of ethical regulatory frameworks of neoliberal ideology) that makes it difficult to infer that she was ethical as a researcher. We may infer that Stolp is unreflexive about her lack of engagement with these ethical principles in her thesis and also in her two articles (Stolp 2016a, 2016b). But, might the problem not be with principlism itself? I shall return to this question in the conclusion of the article where I propose a shift from a transcendent ethics to an immanent ethics. Before doing so I first discuss the matter of self-interest and responsibility in relation to the Stolp case, which I am unable be explore in any detail.

All activities in a university are driven by human selfinterest. And so we might ask, what were Stolp's selfinterests? Were they, the interest to attain a $\mathrm{PhD}$ and the personal and professional benefits that derive from holding a PhD? And what about her self-interests related to her engagement with a public good concern to critique an untransformed music culture in a university - engaging in public good matters do not erase self-interests. Furthermore, we might ask about the self-interests of the supervisor, Chair of the Department of Music and the internal examiner, selfinterests that have not been laid bare in the exchanges in the five academic articles about the case. Self-interests, of course, are not necessarily negative, but they represent opposing discourses to principlism and might explain the ethical breaches committed by Stolp when doing her research. This links to the question of responsibility. We might ask questions concerning Stolp's responsibility as researcher to act in ethical ways, her supervisor's responsibility to guide the student in the process of becoming ethical and the university's responsibility to create opportunities for $\mathrm{PhD}$ (and other) students to engage with ethics in research as part of doctoral education. And also, what about the university's responsibility to put the necessary infrastructures in place to deal with ethical challenges - in this case we saw university role-players fumble at times, the university deviating from its policies, not having its procedural 'ducks in a row' and so forth, which made for a drawn out and messy case. But, a case from which we might learn.

\section{Conclusion: Towards an immanent ethics}

Halse (2011) raises the critical question as to whether we can be in the university and be an ethical researcher given the conflicting discourses of ethics that co-exist in the neoliberal university. At the end of her article Halse (2011) points out that in order to have ethical researchers in the university, we do not need:

[A] coercive technology for disciplining researchers but as a moral beacon for those occasions when rational self-interest causes students, academics and universities to fumble or neglect their responsibilities to others. (p. 250)

The problem with principlism and even more its application in ethical regulation (in the neoliberal university) is that it is driven by a transcendent ethics - ethics is codified and imposed from the outside through mechanisms of control. Principlism functions on rules linked to the obligatory. Liberating ourselves from the fetters of neoliberal ethical regulation and overcoming the challenges presented by conflicting ethical discourses might be possible through practicing an immanent ethics rather than a transcendent ethics. Smith (2011) argues that an immanent ethics draws the distinction between ethics and morality. Morality is defined as a set of constraining rules that guide and judge our actions and intentions. Janning (2015) avers that moralistic questioning aims at leading one in the right direction and that the direction has already been defined before the question is asked. He states that in contrast ethics is a set of assisting rules that helps one in evaluating what one is doing, thinking and feeling 'according to the immanent existence it implies' (Janning 2015:495). Morality asks, 'What ought we to do?' whereas ethics asks, 'What might we do?' So, if 'ethical' principles are to serve as beacons for directing us in the right direction then they belong in the realm of morality. In contrast, ethics requires all principles and ethical discourses to be put to the test, to be evaluated so that new values can be created - values that liberate us from ethical regulation in the neoliberal university. To be in the university and to create the possibility of being or becoming an ethical researcher requires all of us to put all our values, norms and principles to the test and to create new ones. In her book on Deleuze and Guattari's immanent ethics, Lorraine (2011) writes:

Deleuze and Guattari's conception of an immanent ethics calls on us to attend to the situations of our lives in all their textured specificity and to open ourselves up to the responses that will best serve the evolving capacities of the interdependent lifeforms of the communities to which we belong. (p. 1) 
Research, particularly social research, is by nature layered and complex and every situation is unique and therefore requires unique responses - the Stellenbosch university case aptly demonstrates this. We therefore cannot attend to such situations through regulation or principles that are linked to the obligatory. An immanent ethics also negates rational selfinterest because our becoming as researchers is in intra-action with others, both human and more-than-human. So to be an ethical researcher in the contemporary university means attending to situations as they unfold and to act in ways that will enhance life (including one's own in intra-action with others) - the only constraint on our actions is life itself. What it means to be ethical in the university cannot be known in advance. Therefore, De Marco's (2005) mutuality principle cannot rescue principlism from the limits of its transcendent nature.

\section{Acknowledgements Competing interests}

The author has declared that no competing interest exists.

\section{Authors' contributions}

The author declares that he is the sole author of this article.

\section{Ethical consideration}

This article followed all ethical standards for carrying out research without direct contact with human or animal subjects.

\section{Funding information}

The research received no specific grant from any funding agency in the public, commercial or not-for-profit sectors.

\section{Data availability statement}

Data sharing is not applicable to this article as no new data were created or analysed in this study.

\section{Disclaimer}

The views and opinions expressed in this article are that of the author and do not necessarily reflect the official policy or position of any affiliated agency of the author.

\section{References}

Baier, K., 1993, 'Egoism', in P. Singer (ed.), A companion to ethics, pp. 197-204, Blackwell, Oxford.

Ball, S., 2003, 'The teacher's soul and the terrors of performativity', Journal of Education Policy 18(2), 215-228. https://doi.org/10.1080/0268093022000043065 Beauchamp, T. \& Childress, J., 1985, Principles of biomedical ethics, Oxford University Press, Oxford.
Department of Health, 2015, Ethics in health research: Principles, processes and structures, Department of Health, Pretoria.

De Marco, J.P., 2005, 'Principlism and moral dilemmas: A new principle', Journal of Medical Ethics 31(2), 101-105. https://doi.org/10.1136/jme.2004.007856

Demez, H., 2015, 'What is a case, and what is a case study?', Bulletin de Méthodogie Sociologique 127(1), 43-57. https://doi.org/10.1177/0759106315582200

Guta, A., Nixon, S.A. \& Wilson, M.G., 2013, 'Resisting the seduction of "ethics creep": Using Foucault to surface complicity and contradiction in research ethics review', Social Science \& Medicine 98, 301-310. https://doi.org/10.1016/j. socscimed.2012.09.019

Haggerty, K.D., 2004, 'Ethics creep: Governing social science research in the name of ethics', Qualitative Sociology 27, 391-414. https://doi.org/10.1023/B:QUAS.0000 049239.15922.a3

Halse, C., 2011, 'Confessions of an ethics committee chair', Ethics and Education 6(3), 239-251. https://doi.org/10.1080/17449642.2011.632718

Herreid, C.F., 1997, 'What is a case? Bridging to science education the established teaching tool of law and medicine', Journal of College Science Teaching 27(2), 92-94.

Horn, L., Van Niekerk, A., Theron, T., Swartz, L. \& Le Grange, L., 2016, 'Power and ethics in humanities research: A response to Stolp', Acta Academica 48, 1-15. https://doi.org/10.18820/05872405/aa48i2.2

Janning, F., 2015, 'Towards an immanent business ethics?', Asian Journal of Humanities and Social Studies 3(6), 492-500.

Kruger, M., Ndebele, P. \& Horn, L., 2014, Research ethics in Africa: A resource for Research Ethics Committees, African Sun Media, Stellenbosch.

Le Grange, L., 2009, 'How would Ludwig Wittgenstein have performed in the current South African higher education system?', South African Journal of Higher Education 23(4), 629-634. https://doi.org/10.4314/sajhe.v23i4.51052

Le Grange, L., 2014, 'Currere's active force and the Africanisation of the university curriculum', South African Journal of Higher Education 28, 1283-1294.

Le Grange, L., 2016, 'Decolonising the university curriculum', South African Journal of Higher Education 30(2), 1-12. https://doi.org/10.20853/30-2-709

Lorraine, T., 2011, Deleuze and Guattari's immanent ethics, Suny Press, Albany.

Lüdemann, W., 2017, 'Power and ethics in humanities research: Another response to Stolp', Acta Academica 49(2), 1-10.

NHMRC, ARC \& UA, 2007, National statement on ethical conduct in human research, viewed 27 June 2020, from https://www.nhmrc.gov.au/about-us/publications/ national-statement-ethical-conduct-human-research-2007-updated-2018.

Olssen, M. \& Peters, M., 2005, 'Neoliberalism, higher education and the knowledge economy: From the free market to knowledge capitalism', Journal of Education Policy 20(3), 313-45. https://doi.org/10.1080/02680930500108718

Peters, M.A., 2007, Knowledge economy, development and the future of higher education, Sense Publishers, Rotterdam.

Peters, M.A., 2013, 'Managerialism and the neoliberal university: Prospects for new forms of "open management" in higher education', Contemporary Readings in Law and Social Justice 5(1), 11-26.

Rand, A., 1964, The virtue of selfishness: A new concept of egoism, Signet, New York, NY.

Rose, N., 1999, Powers of freedom: Reframing political thought, Cambridge University Press, Cambridge.

Sigwick, H., 1874, The methods of ethics, 7th edn., Macmillan and Co, London.

Smith, D.W., 2011, 'Deleuze and the question of desire: Towards an immanent theory of ethics', in D.W. Smith \& N. Jun (eds.), Deleuze and ethics, pp. 123-141, Edinburgh University Press, Edinburgh.

Stellenbosch 2020. 'Research Ethics Committee: Social, behavioural and education research (REC: SB)', Terms of reference and standard operating procedures, Stellenbosch University, Stellenbosch.

Stolp, M., 2016a, 'Report to the academy: Power and ethics in humanities research', Acta Academica 48(1), 1-26. https://doi.org/10.18820/24150479/aa48i1.1

Stolp, M., 2016b, 'Response to the academy', Academica Academica 48(2), 16-17. https://doi.org/10.18820/05872405/aa48i2.8

Sutherland-Smith, W. \& Saltmarsh, S., 2011, 'Guest editorial: In search of the ethical university', Ethics and Education 6(3), 213-215. https://doi.org/10.1080/1744964 2.2011.632713

Walker, T., 2009, 'What principlism misses', Journal of Medical Ethics 35(4), 229-231. https://doi.org/10.1136/jme.2008.027227

Wall, S., 2008, 'Easier said than done: Writing an autoethnography', International Journal of Qualitative Studies 7(1), 38-53. https://doi.org/10.1177/1609406 90800700103

Walton, C., 2017, 'Of ethics and incompetence', Acta Academica 49(1), 1. 